\title{
The nexus of soil radon and hydrogen dynamics and seismicity of the northern flank of the Kuril-Kamchatka subduction zone
}

\author{
Pavel P. Firstov $\left({ }^{1}\right)$, Valentina S. Yakovleva $\left({ }^{2}\right)$, Vladimir A. Shirokov $\left({ }^{1}\right)$, Oleg P. Rulenko $\left({ }^{1}\right)$, \\ Yury A. Filippov $\left({ }^{1}\right)$ and Olga P. Malysheva $\left(^{1}\right)$ \\ (1) Institute of Volcanology and Seismology FEB RAS, Petropavlovsk-Kamchatsky, Russia \\ (') Tomsk Polytechnic University, Tomsk, Russia
}

\begin{abstract}
The comparison of kinematics and dynamic parameters of radon and molecular hydrogen concentration in subsoil air on the stations network at the Petropavlovsk-Kamchatsky geodynamic proving ground with seismicity of the northern flank of the Kuril-Kamchatka subduction zone was fulfilled in the period from July till August 2004. On the basis of correlation analysis of the regional seismicity and variations of radon flux density calculated using the data of gas-discharge counters of STS-6 type and SSNTDs it was shown that the radon mass transfer abnormal variations are conditioned by both regional seismicity in total and the subduction zone of proving ground. The azimuths of «geodeformation waves» coming to the registration points are calculated during clearly expressed anomaly beginnings, which coincide with directions to earthquake epicenters taking place at the same time. The geochemical anomalies recorded are presumptively deformative by nature and can be conditioned by processes of «quasi-viscous» flow of the lithosphere during rearrangement of tectonic stress fields of the subduction zone. The short-term (predicted time $T<14$ days) precursor of the earthquakes swarm was revealed in hydrogen dynamics on August, 4-5 (four earthquakes had $M \geq 5.3$ and epicentral distance about $130 \mathrm{~km}$ from the Paratunka base station).
\end{abstract}

Key words radon - hydrogen - seismicity - geodeformation wave - earthquake

\section{Introduction}

For half a century work on soil radon recording was carried out in different geological structures using different equipment and showed the benefits of the seismic-emanation method (Dubinchuk, 1991; King, 1991; Rudakov, 2003).

Mailing address: Dr. Pavel P. Firstov, Institute of Volcanology and Seismology FEB RAS, B. Piip Blvrd 9, Petropavlovsk-Kamchatsky 683006, Russia; e-mail: firstov@kscnet.ru
Therefore, further development and perfection of this method, both in methodical (Steinitz et al., 1999, 2003; Utkin, 2000) and technical (Kim et al., 1997) aspects, is an essential goal for earthquake forecasting purposes.

A network for subsoil radon monitoring was created at the Petropavlovsk-Kamchatsky geodynamic proving ground in 1997-2000 with the purpose to search for the precursors of the Avacha Gulf strong earthquakes (Firstov, 1999; Firstov and Rudakov, 2003). The network was extended and modernized in the following years.

This report analyses the features of the soil radon mass transfer response to changes in stressed-deformed state of the lithosphere on the northern flank of the Kuril-Kamchatka subduction zone over the period July-August, 2004 
for the purpose of revealing short-term strong earthquake precursors.

\section{Space-time seismic characteristics of research areas and observation techniques}

The network consisting of 4 monitoring stations functioned in the examination period, its coordinates and conditions of detector placement are given in table I. The scheme of location of the monitoring stations is shown in fig. 1 . Two stations were located in the northern part of Paratunka hydrothermal system, which structurally refers to the graben of the southern part of Nachikinskaya fold-blocky zone. A structural feature of the examined area is blocky tectonics (Serezhnikov and Zimin, 1976). The block mo- saic is caused by a combination of motions along long-standing ruptures. The majority of faults are reflected on a relief. Some faults located at the valley of Paratunka River under loose sediments were traced by geophysical methods. The faults divide the whole structure into four main blocks.

The base station «Paratunka» (PRT) is located on the terrace of the Korkina stream, which traces a sublatitude fault of the Paratunka graben. A well developed network of hydrothermal groundwater reservoirs refers to Paratunka graben. Shows of thermal waters with the radon concentration up to $1500 \mathrm{~Bq} \mathrm{~m}^{-3}$ were found in $700 \mathrm{~m}$ away from the PRT station downstream.

The annual radon-hydrogen measurements were conducted across the valley of Korkina stream. Figure 2 shows the schematic profile of

Table I. Coordinates of soil radon monitoring stations of Petropavlovsk-Kamchatsky geodynamic proving ground (July-August, 2004).

\begin{tabular}{|c|c|c|c|c|}
\hline Name of work station & Abbreviation & $\begin{array}{r}\text { Coor } \\
\text { Lat }(\mathrm{N})\end{array}$ & $\begin{array}{l}\text { dinates } \\
\text { Long }(\mathrm{E}\end{array}$ & $\begin{array}{l}\text { Short description of locality and measurement conditions } \\
\text { ) }\end{array}$ \\
\hline $\begin{array}{c}\text { Paratunka } \\
\text { (base station) }\end{array}$ & PRT & 52.90 & 158.26 & $\begin{array}{l}\text { Hydrothermal system, zone of dynamic influencing of } \\
\text { the fault, which is traced by the Korkina stream. } \\
\text { Radon measurements were made by radiometer «REVAR» } \\
\text { with } 2 \text { gas-filled counter tubes (STS- } 6 \text { type). Two depths } \\
\text { of radon measurements (point } 1 \text { - zone of aeration; point } 2 \text { - } \\
\text { zone of the full water saturation). }\end{array}$ \\
\hline $\begin{array}{l}\text { Institute of } \\
\text { Cosmophysical } \\
\text { Researches } \\
\text { and Radio Wave } \\
\text { Propagation }\end{array}$ & IKR & & & $\begin{array}{l}\text { Terrace of the Paratunka River ( } 2 \mathrm{~km} \text { from a bank). } \\
\text { Two depths of radon measurements (point } 1-0.8 \mathrm{~m} \text { and } \\
\text { point } 2-1.35 \mathrm{~m} \text { ). }\end{array}$ \\
\hline Left Avacha & LVCh & 53.50 & 158.19 & $\begin{array}{l}\text { Left Avacha River fluvial terrace }(150 \mathrm{~m} \text { from bank). } \\
\text { A fissile fault, two variable-depth points in a zone of } \\
\text { aeration (point } 1-0.9 \text { and point } 2-1.9 \mathrm{M}) \text {. }\end{array}$ \\
\hline $\begin{array}{l}\text { Institute of } \\
\text { Volcanology } \\
\text { and Seismology }\end{array}$ & INS & 53.07 & 158.61 & $\begin{array}{l}\text { Geology: sediments of old pyroclastic streams. } \\
\text { Radon measurements were made in: } \\
\text { Point } 1 \text { - inside the basement of the Institute building. } \\
\text { Point } 2 \text { - inside a bunker of drilled hole at point } 1 \text {, zone of } \\
\text { aeration. } \\
\text { Point } 3 \text { - inside a casing pipe of a drilled hole on depth of } \\
5 \mathrm{~m} \text {. } \\
\text { Point } 4 \text { - measurement of radon flux from the earth surface } \\
\text { in a bunker. }\end{array}$ \\
\hline
\end{tabular}




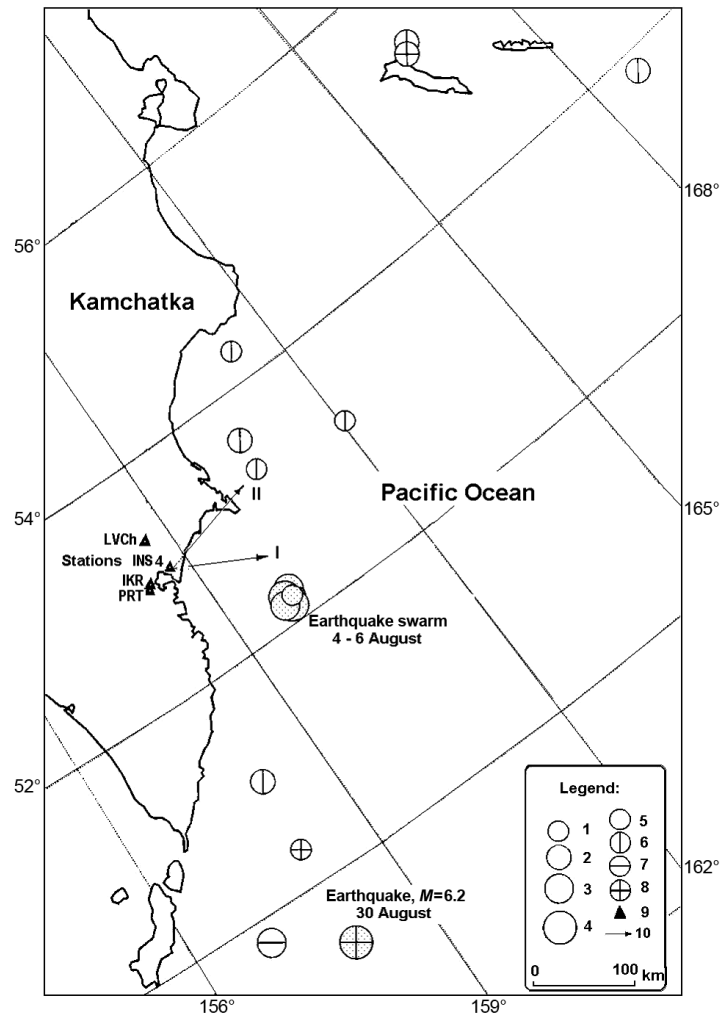

Fig. 1. The scheme of location of radon monitoring stations over the period of July-August 2004 and earthquake's epicenters for the period of July 12-September 1, 2004, with energy class $(K): \mathbf{1}-11 ; 2-12 ; \mathbf{3}-13$; 4 - 14; and a focal depth: 5 - 0-19; 6 - 20-39; 7 - 4059; 8 - 60-100 km; 9 - monitoring stations; 10 - azimuth to the epicenter.

the stream valley, radon-hydrogenous monitoring results and placement of measure points on the PRT station. The concentration of molecular hydrogen in soil air was measured by a hydrogen geophysical signaling device model VSG-2, in relative units ( $\mathrm{mV}$ ), and radon concentration was measured by a radiometer model «RGA-1».

High values of radon concentration and hydrogen concentration were recorded at two sites of the profile: on the left-hand slope and at the bottom of the valley. These sites should be attributed to disjunctive ruptures characterized by high permeability. The gas-filled counter tubes for continuous radon measurement were placed on those sites of the profile where the background level was observed, which proved to be evidence of the quasi-homogeneity of the medium.

The second station (IKR) is located in the territory of the Institute of Cosmophysical Researches and Radio Wave Propagation. Another two stations are located in the region of Petropavlovsky horst. The station «Left Avacha» (LVCh) is located at the bank of the Left Avacha River within the fault zone, traced by a river-bed. The fourth station (INS) is located in the territory of Institute of Volcanology and Seismology.

All stations are equipped with REVAR radiometers. Passive measurements will be used on the basis of a chamber with an electrostatic field, in which the sensor is the gas-discharge Geiger counter registering $\beta$-radiation decomposition product ${ }^{222} \mathrm{Rn}$. It allows autonomous long-time observations to be performed with duration of a time period of accumulation from $10 \mathrm{~s}$ to $99 \mathrm{~h}$ with a step of $1 \mathrm{~s}$. The stored data are saved in a plug-in module of a storage and are then transferred in the PC through a serial port RS-232. At the PRT station the Rn concentration was measured in alluvial-sandy sediments at a depth of one meter from the surface at two points: aeration zone (point 1, fig. 2) and total water saturation zone (point 2, fig. 2). Two gas-filled counter tubes of the REVAR radiometer were put in alluvial-clay sediments on 2 depths (table I).

In addition to standard radon measurements by instantaneous method, radon measurements by an integrated method with SSNTDs at point 3 (fig. 2) were carried out at different depths for the period from July 12 till August 26, 2004. Two holes spaced $0.5 \mathrm{~m}$ apart were drilled by a customized soil auger; one hole was $50 \mathrm{~cm}$ deep, and the other was $100 \mathrm{~cm}$ deep. A plastic pipe casing with diameter $5.5 \mathrm{~cm}$ was inserted into the hole. Radon radiometers with tracketch detectors of LR-115 type III-b (Nikolaev and Iliç, 1999) were placed in the holes. Then, the holes were covered to be air-tight and left for $96 \mathrm{~h}$. The soil gas radon concentration was determined for the AIST-TRAL complex by the 


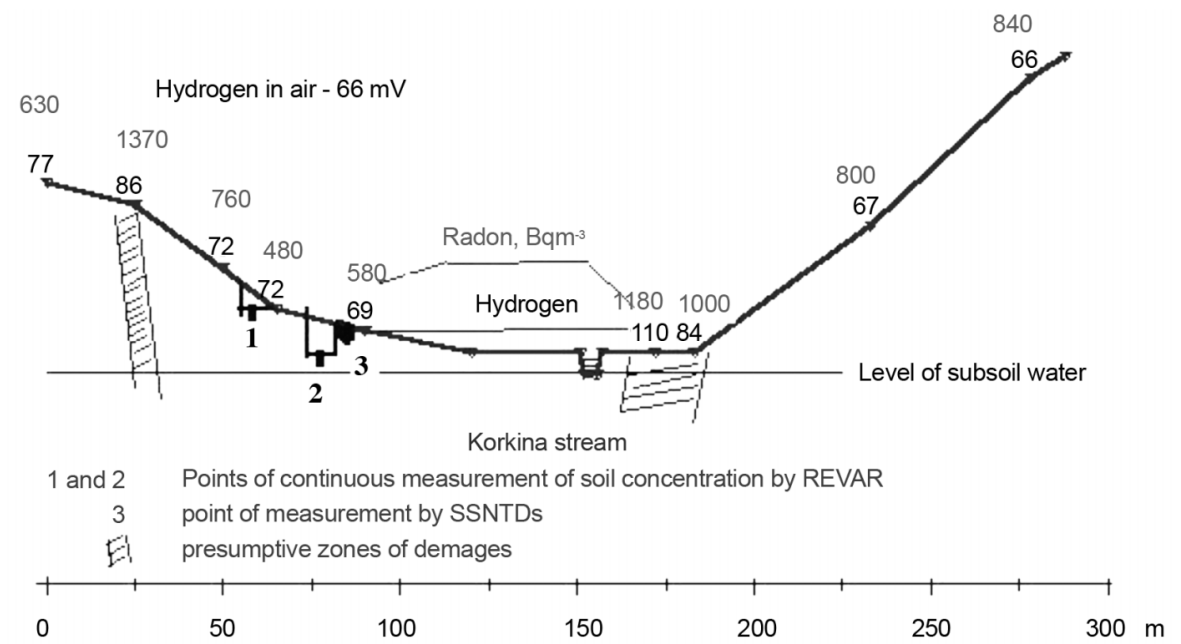

Fig. 2. Schematic structural map of the PRT station's area and results of radon-hydrogen measurements across the valley of Korkina stream.

method described elsewhere (Yakovleva, 2005). The etching and track counting methodology are described elsewhere (Nikolaev et al., 1993).

The space-time characteristics of seismicity were studied using the operative catalogue of Kamchatka Experimental-Methodical Seismological Department of Geophysical Service, RAS.

\section{Results of observation for radon concen- tration and hydrogen concentration in subsoil air}

The results of radon monitoring for the period from July 12 to September 1, 2004 are given in fig. 3a-c. Solid lines mark the moments of strong earthquakes which occurred on south Kamchatka (4th and 30th August) and the time of stepwise radon anomaly observed on August 16. The temporal dynamics of air temperature, pressure and precipitations are given in fig. $3 \mathrm{~d}$.

Figure 3a shows the dynamics of radon concentration at the PRT base station at two points. Triangles mark the phase correlation between the signals of 4th and 16th August. Firstov and Rudakov (2003) found that synchronous increasing of radon concentration at both zones of full water saturation and the aeration zone (like that on August 4; fig. 3a) testifies the increase in convective soil gas velocity resulting from changes in stressed-deformed state of the geological medium. It should be noted that the positive anomaly of August 4-6 was also observed at both points of the station IKR (fig. 3b) located within Paratunsky graben. At two other stations (INS and LVCh) the anomalies were not observed with an abrupt front (fig. 3b).

The weaker anomalies, which were qualitatively similar to previous ones in their forms, were recorded at all stations on August 12. The anomaly of 16th August represents a synchronous decrease of radon concentration at both points of Station PRT and nearly stepwise decrease at other Stations (fig. 3b). Anomalies of 4th and 16th August were also observed in the data obtained by SSNTDs (fig. 3c).

Figure 4a,b shows detailed dynamics of radon concentration at the stations IKR, INS and $\mathrm{LVCh}$, forming a triangle with an aperture of about $70 \mathrm{~km}$ for the periods of August 3-6 (a) and 15-17 (b). It is conditionally possible to separate the moments of the beginning anomalies and to determine the time of their delay comparatively to the Station INS. Assuming that the front of the incoming wave is plane, the azimuths 

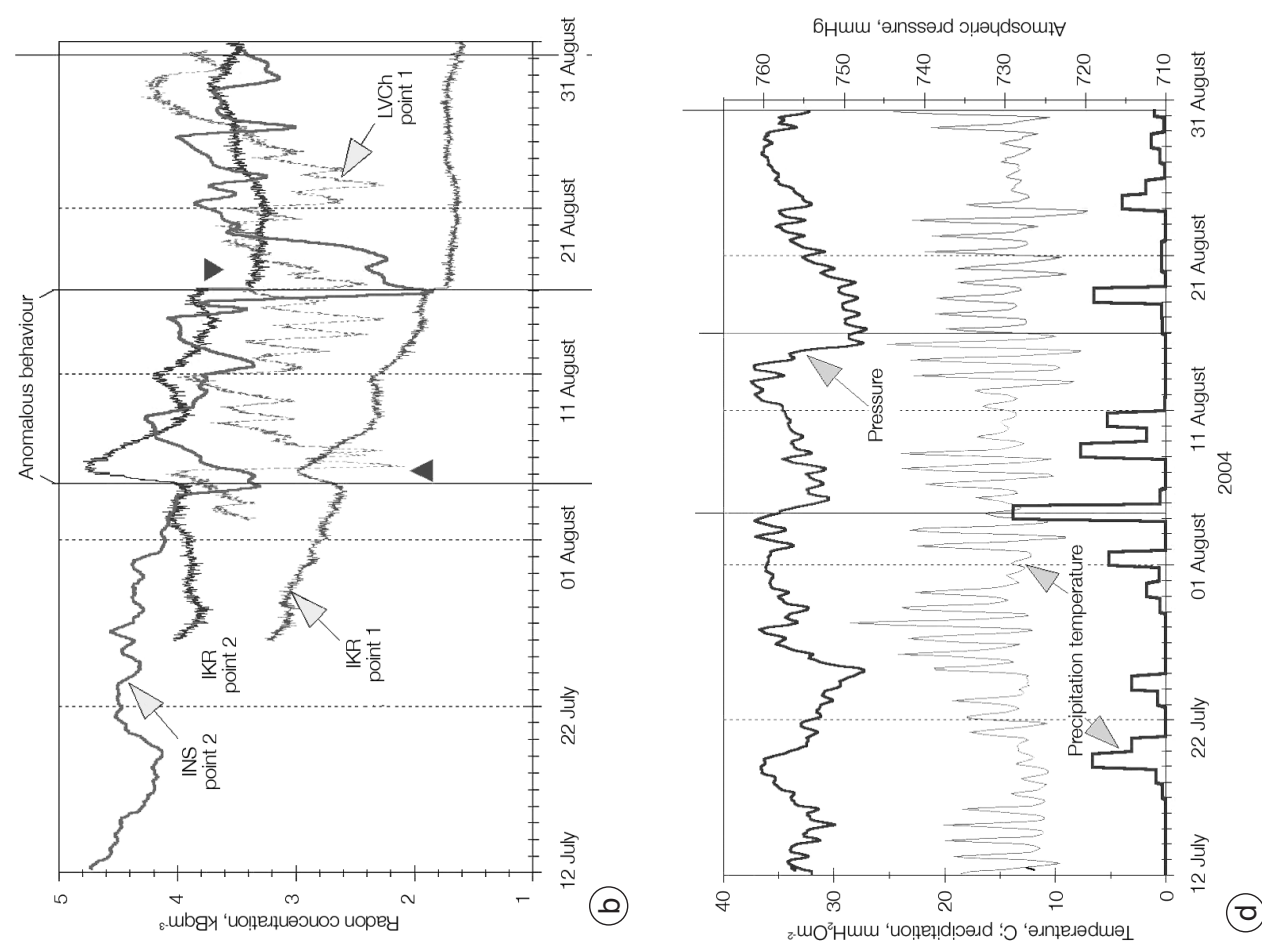

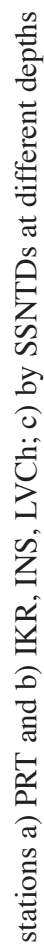
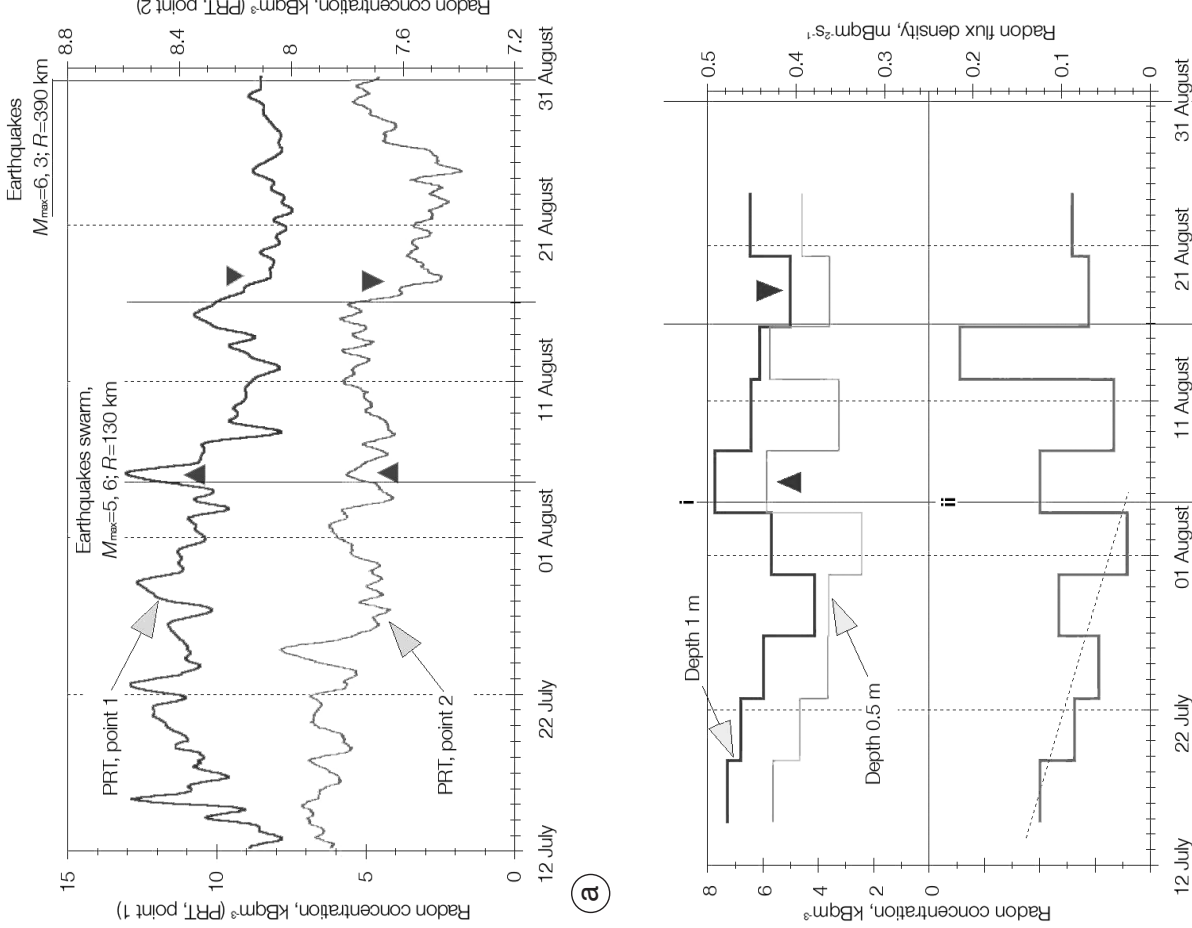

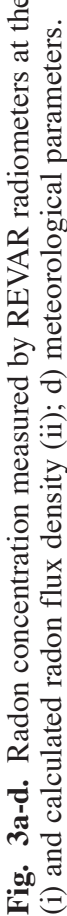




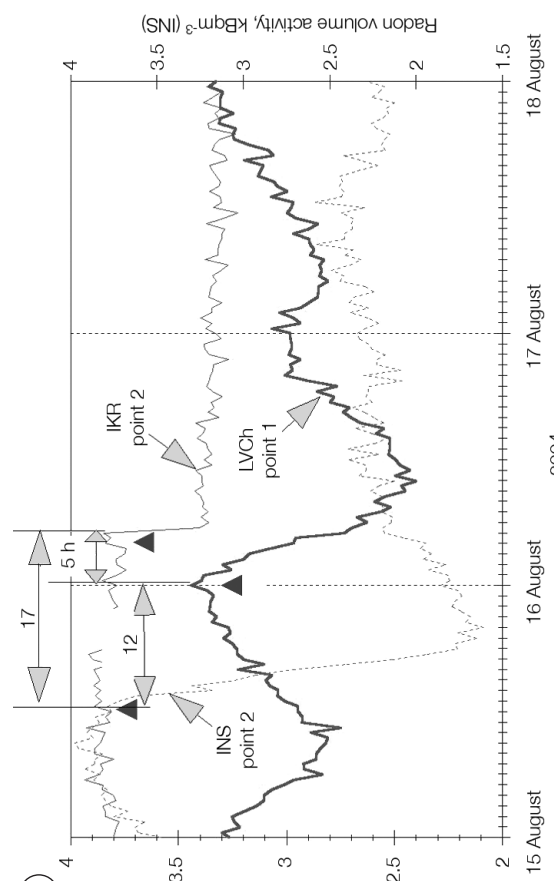

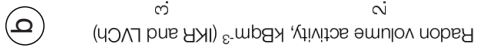

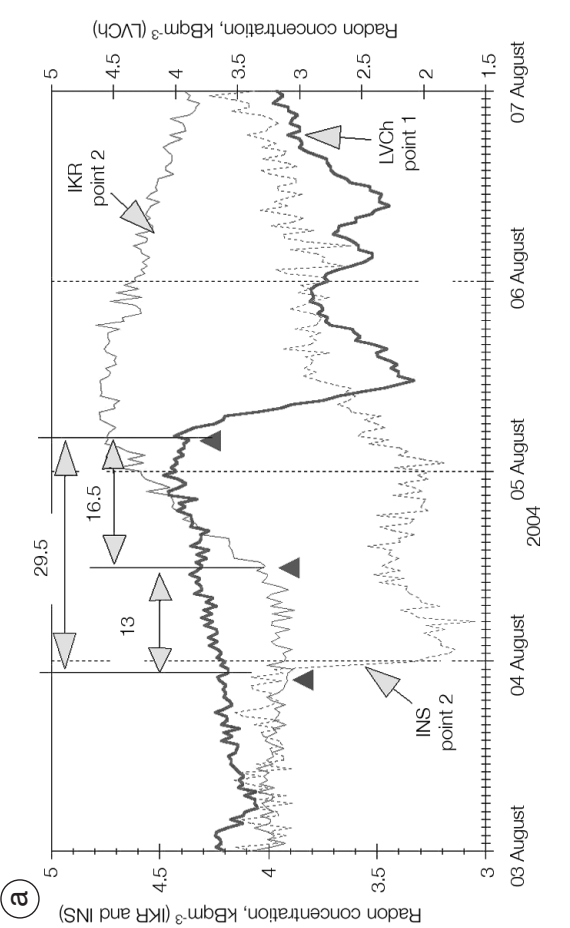

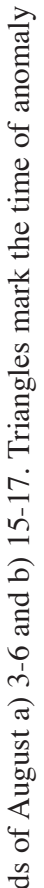

용

$\stackrel{8}{E}$

t)

ป

吾

ส

岂

幽

气

善

$\stackrel{\Xi}{ \pm}$

茴

$\stackrel{\Xi}{\Xi}$

灾.

휴 해

论

亲

+ 藏

일

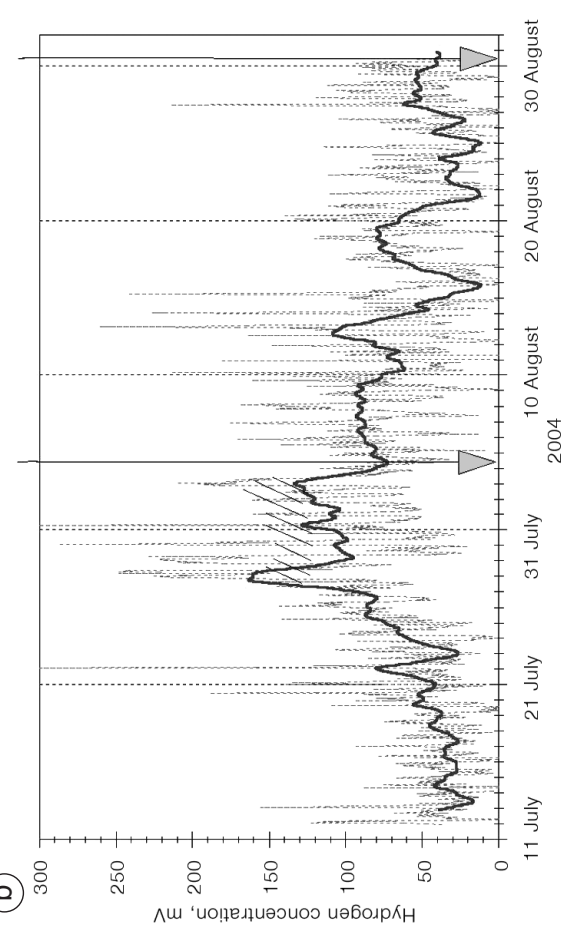

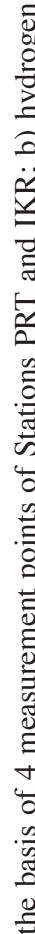
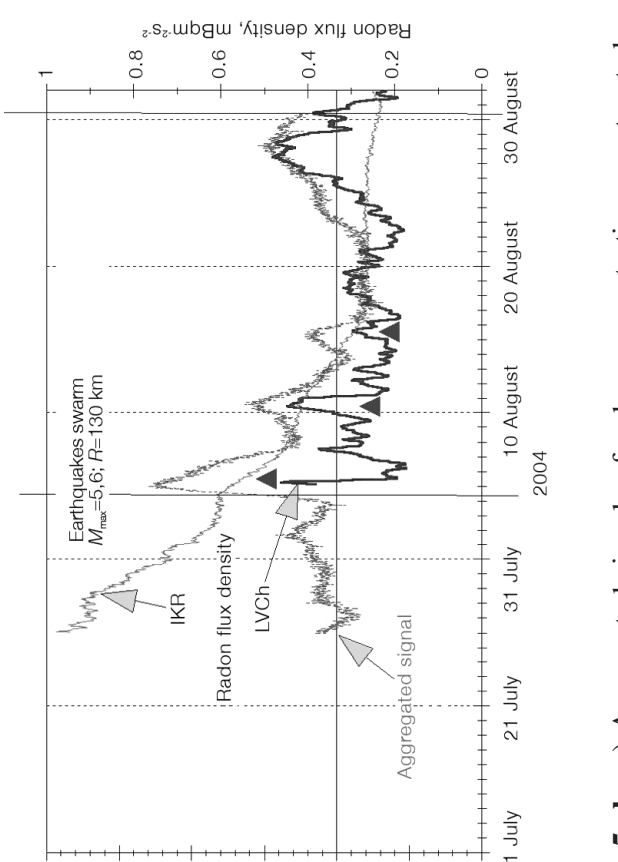

(๘) 
of its arrival were calculated accounting for the differences in the coming delay for the Stations IKR and $\mathrm{LVCh}$ and it was $105^{\circ} \pm 15^{\circ}$ in the first case and $72^{\circ} \pm 13^{\circ}$ in the second (fig. 1).

For those stations where the radon concentration was observed at two different depths, the values of radon flux density from the Earth's surface were calculated by the formula (Yakovleva, 2005):

$$
\left.q(z)\right|_{z=0}=D_{e} \eta \cdot \frac{A_{1}}{2-\frac{A_{2}}{A_{1}}} \cdot \frac{1}{h_{1}} \cdot \ln \left(\frac{1}{\frac{A_{2}}{A_{1}}-1}\right)
$$

where $A_{1}$ and $A_{2}$ are the radon concentrations at depths $h_{1}$ and $h_{2}=2 h_{1} ; D_{e}$ is the radon diffusion coefficient; $\eta$ is the soil porosity. For poorly humidified alluvial sediments with a porosity of about $23 \%$ the diffusion coefficient $0.0055 \mathrm{~cm}^{2} \mathrm{~s}^{-1}$ was considered (Novikov, 1989). The values of radon flux density were calculated with the use of eq. (3.1) for the IKR and LVCh stations (fig. 5a) and the PRT station (fig. 3c).

To reveal the common tendencies in behavior of radon concentration within Paratunka graben the aggregated signals were constructed on the basis of a four-dimensional data sequence (2 measure points of Stations PRT and IKR) with the use of Ljubushin's methods (Ljubushin, 1998). Aggregated signals clearly reveal the anomaly of 4th August and weaker disturbances of 11th and 16th August that are marked by triangles (fig. 5a).

Figure $5 b$ shows the temporal dynamics of molecular hydrogen concentration in subsoil air (dashed line). A clearly defined positive correlation between hydrogen concentration and air temperature is observed (the correlation coefficient, $r=0.4)$. The hydrogen concentration compensated for temperature by Ljubushin's methods and averaged by moving mean on 24 points is marked by a full line. Two months' average value was found to be $64 \pm 40 \mathrm{mV}$. In the period from July 27th till August 4th the measured values exceed $100 \mathrm{mV}$ (the average value plus standard deviation), therefore, as a first approximation, this period can be counted as abnormal.

Due to the deep origin the response to changes in the stressed-deformed state of the lithosphere would be observed in hydrogen dynamics much earlier than in soil radon dynamics. Therefore, it is possible to consider the marked excess of hydrogen concentration as a short-term precursor of the earthquake swarm of August 4-5 with $M_{\max }=5.6$ and epicentral distance of $130 \mathrm{~km}$ from the registration point.

\section{Seismicity of the northern flank of the Kuril-Kamchatka subduction zone}

The earthquakes which occurred in the Kuril-Kamchatka region reflect the time reorganization of seismotectonic stress fields connected with interaction processes between $\mathrm{Pa}$ cific and Eurasian tectonic plates. From 10th July till 31st August 2004 an investigation of space-time seismicity characteristics of the northern flank of the Kuril-Kamchatka subduction zone stretching from Commodore Islands in the north up to Paramushir Island in the south was carried out.

Figure 1 shows the map of earthquake epicenters constructed on the basis of operative data of Kamchatkan Experimental and Methodical Seismological Department, Geophysical Service, RAS. The map indicates the earthquakes with energy class $K \geq 10.5(K=\log E, \mathrm{~J})$ for cross waves and hypocenter depth $h \leq 100$ $\mathrm{km}$ occurred on the northern flank of the KurilKamchatka subduction zone. The time distribution of these earthquakes is shown in fig. $6 \mathrm{~b}$.

The value of seismotectonic movement velocity depends mainly on the number of seismic events $(N)$ per unit of time and much less on other parameters of a seismic mode. At first, the value of seismotectonic movement velocity can be estimated by a density of events with $K \geq$ $\geq 10.5$ per unit of time $(n=N / t)$ within an examined seismoactive volume (Riznichenko, 1977). The velocity determines a slope of the earthquakes cumulative number plot. The size of seismotectonic movement velocity determines four phases of seismic activity on (fig. 6a): I July, 12-August, 3; II - the earthquake swarm in Avachinsky gulf on August, 4-6; III - August 7-15; IV - August, 16-30.

In the first phase, the value $n$ was close to the background value. In phases II and IV the 

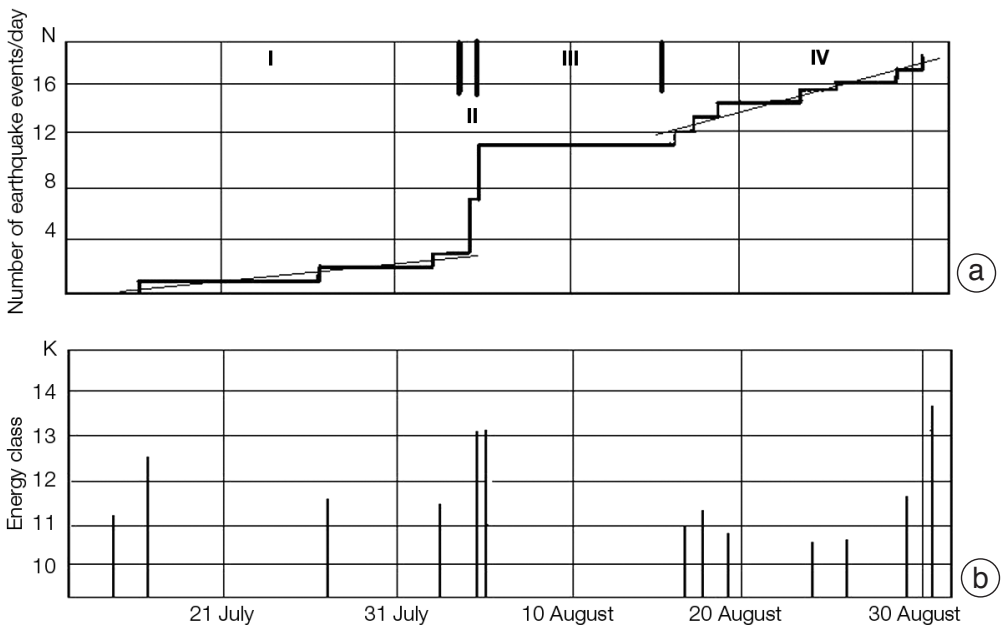

Fig. 6a,b. Events of earthquakes a) with energy class $K \geq 10.5$ per a day; b) maximal energy class.

value $n$ considerably exceeds the background value. However, if in phase II the seismic process was located in a small area of Avachinsky gulf, the earthquakes of phase IV occurred within all examined territory covering the Komandor islands in the North up to Paramushir Island in the South (fig. 1). The last circumstance denotes the regional effect of increase in seismotectonic movement velocity, which may possibly be caused by an increase in the speed of the moving Pacific Plate.

\subsection{Results analysis}

Let us compare the data of radon-hydrogen monitoring with the denoted phases of seismic activity. Phase I is apparently connected with relaxation of tectonic stress field after last year's strongest earthquake in Kamchatka on 10th June, 2004. This earthquake had $K=14.0$ $(M=6.4), h=200 \mathrm{~km}$ and occurred at the Kronotsky Cape area. Due to relaxation processes which developed 16 days after this earthquake, a swarm of shallow-focus earthquakes $\left(K_{\max }=\right.$ $=11.6$ ) took place in the same area on June 2627 th and the following more powerful swarm of earthquakes $\left(K_{\max }=13.0\right)$ took place on August 4-6 in the adjacent Avachinskaya «key».
Apparently increasing seismotectonic deformations preceded this swarm in the Avachinskaja «key» area which triggered an appropriate decrease of radon flux density at the Paratunka graben area (stations PRT and IKR) and an 8 day anomaly in a hydrogen concentration at the PRT station (fig. 5a,b).

In recent years many researchers have focused on the rheological properties of a geological material and have devised a model of earthquake preparation process. Morgunov (2001) in his work showed that in a focal zone a stage of qua$s i$-viscous rock flow results from creep preceding a brittle rupture or an earthquake. The minimal time of this stage is estimated at not less than $10 \mathrm{~h}$ before a seismic event. Let us consider the radon anomaly of August 4-5 in more detail. We will presumably consider the anomaly as a reaction of a soil radon field on the rock deformation resulting from quasi-viscous flow of geological material (in other words «a geodeformation wave»). This assumption is supported by the fact that the azimuth of the anomaly incoming to the radon monitoring stations is close to the direction towards the epicenter area of the earthquakes swarm of August 4 (fig. 1). This anomaly had started to shape (in aggregated signal) $11 \mathrm{~h}$ before the beginning of the earthquake swarm (fig. 5a) which allows it to be considered a short-term precursor. 
As shown in Ljubushin's experimental work (Ljubushin, 1993) the «geodeformation waves» influencing radon field and anomalies have various shapes depending on a location of measurement points relative to borders of different blocks.

In phase III a speed of seismotectonic movement was much lower than the background value which, in our opinion, reflects a stage of qua$s i$-viscous creep within the whole seismic zone. At the final stage of this phase (August 15-16) a speed of plastic deformations caused by quasiviscous flow was increased and resulted in generation of a «geodeformation wave» owing to dislocation of blocks. It was reflected in a radon field as an anomaly. Azimuth of its incoming is close to a direction on epicenter of the first earthquake $(K=10.9)$ of phase IV which occurred on August 16 in the south of Kronotsky gulf (fig. 1).

Researchers at the Institute of Volcanology and Seismology at Kamchatka also revealed anomalies on August 15-16 in other geophysical fields.

\section{Conclusions}

On the basis of our analysis the following conclusions were derived:

1) The network of radon monitoring Stations of Petropavlovsk-Kamchatsky geodynamic proving ground during the period June-August recorded abnormal behavior on August 4-5 and 16, which was interpreted as the reaction of a soil radon field to «geodeformation waves» caused by plastic deformations in a subduction zone.

2) On the basis of the analysis of spacetime seismic characteristics the four phases of seismic activity were defined on the northern flank of Kuril-Kamchatka islands line.

3) A satisfactory correlation was found between temporal dynamics of radon concentration and space-time characteristics of seismicity was found. Moreover, the abrupt increase in the amplitude of the aggregated signal $11 \mathrm{~h}$ before a swarm of earthquakes on August 4-5 can be considered a short-term precursor.

4) The increase in molecular hydrogen concentration in subsoil air recorded at Station
PRT before a swarm of earthquakes $\left(M_{\max }=5.6\right.$ and $h=130 \mathrm{~km}$ ) on August 4-5 exceeds the average value by two, which could be considered a short-term precursor.

\section{Acknowledgements}

The work was undertaken with financial support of RFBR No. 02-05-64556, the grant of the President of the Russian Federation No. MK-3295.2004.5 and governmental scientific program «The Development of scientific potential of the Higher Schools» under the Section 1.2 «Universities of Russian Federation» No. ur.09.01.416.

\section{REFERENCES}

DubinchuK, V.T. (1991): Radon as a precursor of earthquakes, in Isotopic Geochemical Precursors of Earthquakes and Volcanic Eruption, Vienna, 37-42.

FIRSTOV, P.P. (1999): Monitoring of subsoil radon volumetric activity on Paratunka geothermal system in 1997 1998 with the purpose to search for the precursors of strong earthquakes of Kamchatka, Volcanol. Seismol., 6, 1-11 (in Russian).

Firstov, P.P. and V.P. RUdAKOv (2003): Results of subsoil radon registration in 1997-2000 on the Petropavlovsk Kamchatsky geodynamic polygon, Volcanol. Seismol., 1, 26-41 (in Russian).

KIM, I.S., A. AHHLEBy and G.H. Sigel JR. (1997): Observation of the trapping of radioactive inert gas radon on oxide glass surfaces: macroporous scintillating-glassfiber bundle alpha detector, Nucl. Instrum. Methods Phys. Res., A390, 419-422.

KING, C.-Y. (1991): Gas-geochemical approaches to earthquake prediction, in Isotopic Geochemical Precursors of Earthquakes and Volcanic Eruption, Vienna, 22-36.

LJUBUSHIN, A.A. JR. (1993): The multivariate analysis of time series of systems of geophysical monitoring, Phys. Earth, 1, 103-108 (in Russian).

LJUBUSHIN, A.A. JR. (1998): The aggregated signal of systems of low-frequency geophysical monitoring, Izvestiya (Physics of the Solid Earth), 1, 69-74 (in Russian).

MorgunOv, V.A. (2001): The creep of the rocks at a finishing stage of preparation of earthquakes, Izvestiya (Physics of the Solid Earth), 4, 3-11 (in Russian).

NiKOLAEV, V.A. and R. Iliç (1999): Etched track radiometers in radon measurements: a review, Radiat. Meas. 30, 1-13.

Nikolaev, V.A., M.G. BuZynniy, I.B.VorobyeV, A.V. GroMOV, A.S. KRIVOKHATSKIY, I.P. LOS, A.V. ZELENSKIY and Yu.A. Tomilin (1993): Application of the track method for radon measurements in Ukraine, Nucl. Tracks Radiat. Meas., 21 (3), 433-436.

Novikov, G.F. (1989): The Radiometric Exploration, Lenin- 
grad, pp. 406 (in Russian).

RIZNICHENKO, YU.V. (1977): Calculation of speed of deformations at seismic current of mountain weights, Izvestiya (Physics of the Solid Earth), 54-65 (in Russian).

RuDAKOV, V.P. (2003): The seismoemanation effects of geological structures, in Problems of Geophysics of XXI Century. The Book 2 (Znanije Publ., Moscow), 95-113 (in Russian).

SEREZHNIKOV, A.I. and V.M. Zimin (1976): Geological structure of Paratunka geothermal area, influence of separate geological factors on modern geothermal activity, in Hydrothermal Systems and Thermal Fields on Kamchatka, Vladivostok, 115-142 (in Russian).
Steinitz, G., U. Vulkan and B. LANG (1999): Radon flux at the northwestern segment of the Dead Sea (Dead Sea rift) and its relation to earthquakes, Isr. J. Earth Sci., 48, 283-299.

Steinitz, G., Z.B. Begin and N. GaZiT-YAari (2003): Statistically significant relation between radon flux and weak earthquakes in the Dead Sea rift valley, Geology, 6, 505-508.

UTKIN, V.I. (2000): Radon and problem of tectonic earthquakes, SOZh, 6 (12), 64-70 (in Russian).

YAKOVLEVA, V.S. (2005): A theoretical method for estimating the characteristics of radon transport in homogeneous soil, Ann. Geophysics, 48 (1), 195-198. 